\title{
Correction to: Preventing Fall Armyworm (Spodoptera Frugiperda JE Smith) Damage in Maize by Altering Planting Time and Using Varied Genotypes
}

Leonard Nyabanga, Ronald Mandumbu, Joyful T. Rugare, Never Mafuse, Emmanuel Zivenge, Handsen Tibugari, George Nyamadzawo, and Christopher T. Gadzirayi

\section{Correction to: \\ Chapter 4 in G. Nhamo et al. (eds.), Sustainable Development Goals for Society Vol. 2, Sustainable Development Goals Series, https://doi.org/10.1007/978-3-030-70952-5_4}

The original version of this chapter was inadvertently published without updating the correct spelling of the chapter author name "Handsen Tibugari". Now, this has been corrected in the chapter proof and front matter. 